\title{
AGROCOMBUSTÍVEIS E AGRICULTURA FAMILIAR NO BRASIL \\ Conflitos e contradições no alcance da meta social do programa do biodiesel do Piauí
}

\author{
AGROFUELS AND FAMILY FARMING IN BRAZIL \\ Conflicts and contradictions in reaching the social goal of Piauí \\ biodiesel program
}

\author{
Maria Elza Soares da Silva \\ Núcleo de Experimentação Agroecológica- NEA, Universidade Federal do Piauí. Campus Universitário \\ Ministro Petrônio Portella, Bairro Ininga Teresina, 64049-550, Piauí, Brasil. Email: elzasoarespi@gmail.com
}

\begin{abstract}
Resumo: A produção de energia verde com a participação da agricultura familiar tem despertado o interesse do governo e de investidores do agronegócio. No Brasil, o programa do biodiesel apresentou-se como alternativa para a geração de renda para agricultores familiares pobres incluídos na cadeia produtiva do biodiesel. O objetivo deste artigo é analisar os conflitos decorrentes do desafio da conjugação do projeto de produção de agrocombustíveis com as demandas sociais da agricultura familiar pobre no semiárido do Piauí. Para tanto, foi realizada pesquisa de campo para o levantamento de dados qualitativos junto aos agricultores participantes do programa no Sul do Piauí. O estudo demonstrou que o modelo do projeto produtivo tornou-se excludente para aqueles agricultores inseridos na lógica de produção tradicional e de subsistência, desvelando, assim, implicações negativas na forma de acesso às terras e ao mercado do biodiesel.
\end{abstract}

Palavras-chave: reprodução social, agrocombustível, acesso à terra.

\begin{abstract}
The production of green energy with the participation of family farming aroused the interest of the government and agribusiness investors. In Brazil, the biodiesel program showed as an alternative for generating income for poor family farmers included in the biodiesel production chain. This article aims to analyze the conflicts arising from articulating agrofuel production with the social demand of poor family agriculture in the semi-arid region of Piauí. For this purpose, field research was carried out to collect qualitative data from program participants in southern Piauí. The study showed that the model of productive project resulted in the exclusion of farmers within the traditional production and subsistence logic. This has negative implications in accessing land and in the biodiesel market.
\end{abstract}

Keywords: social reproduction, agrofuel, access to land.

\section{Introdução}

A crescente demanda mundial por agrocombustíveis como alternativa aos combustíveis fósseis contribuiu para que o Brasil lançasse, no ano de 2004, o Programa Nacional de Uso e Produção do Biodiesel-PNPB, uma política nacional de uso e produção de biodiesel para atender à demanda da matriz energética brasileira, 
bem como reduzir a pobreza no campo com ações de estímulo à inclusão da agricultura familiar na cadeia produtiva do biodiesel.

O desenho original do PNPB definiu como meta social inicial a inclusão de 200 mil agricultores familiares no mercado do biodiesel, com prioridade para as regiões Norte e Nordeste, consideradas menos desenvolvidas e com maior concentração de agricultores familiares vulneráveis social e economicamente.

Antes do lançamento do PNPB, no ano de 2003 já havia a articulação institucional do extinto Ministério do Desenvolvimento Agrário - MDA com as Secretarias Estaduais de Desenvolvimento Rural e entidades representativas da agricultura familiar nos estados e municípios para adotarem ações necessárias à implementação do programa no ano de 2004.Nessas articulações institucionais, o estado do Piauí foi escolhido para a instalação de um modelo de projeto produtivo que aliasse a política estadual de distribuição de terras para aqueles agricultores sem-terra, através da parceria rural para a produção de oleaginosa com vistas a atender à demanda da usina do biodiesel.

O contexto político à época se apresentava favorável às políticas públicas voltadas para a agricultura familiar no Brasil e no estado do Piauí, cujo governo estadual estava alinhado ao projeto político do Governo Federal. Nesse sentido, firmaram a modalidade jurídica de Parceria Público-Privada - PPP para assentar famílias de agricultores sem-terra no projeto produtivo denominado por Núcleo de Produção Comunitária Santa Clara - NPSC, no município de Canto do Buriti, Sudeste do Piaú, para a produção de mamona (Ricinus communis L), com vistas ao abastecimento da indústria dos agrocombustíveis.

A PPP foi firmada através da Lei Estadual 5.333/2003, em que o estado do Piauí doou uma área de 36 mil hectares de terras agricultáveis para a iniciativa privada assentar até 700 famílias de agricultores familiares sem-terra na condição jurídica de parceiros rurais da Agroindústria processadora de biodiesel.

Uma das singularidades desse modelo de projeto produtivo foi que a lei, ao definir a distribuição de terras ao término da parceria rural, estaria realizando uma "reforma agrária privada" no Piauí. Contudo, faz-se necessário esclarecer que esse entendimento de "reforma agrária" se deve à promessa de doação da titularidade das terras da fazenda para as famílias que permanecessem, no mínimo, dez anos produzindo mamona para atender à demanda da agroindústria parceira. Uma das exigências da lei estadual era que a empresa parceira transferisse os lotes, medindo 25 hectares, para cada família sem ônus para os cofres públicos e tampouco para as famílias contempladas.

Um das críticas que recaem sobre o PNPB é que a produção de energia verde com a participação da agricultura familiar parece deslocada das preocupações 
sobre as consequências ambientais e sociais da produção de novos carburantes. Ademais, uma das problemáticas dos agrocombustíveis é que eles são movidos pelo motor da economia no mercado capitalista das commodities. Como frisa Houtart (2010, p.10), a agroenergia tornou-se uma solução para a crise do capital, e não do clima, como propalado nos discursos hegemônicos.

Nesta perspectiva de análise, problematizamos sobre a natureza dos conflitos decorrentes do desafio da conjugação do projeto de produção de agrocombustíveis com as demandas sociais da agricultura familiar.

Assim, alguns questionamentos secundários nortearam a nossa reflexão para este artigo, sendo eles: a inclusão da agricultura familiar no mercado do biodiesel associada à distribuição de terras contribuiu para o fracasso do projeto-piloto do programa do biodiesel no estado do Piauí? Quais foram os desafios enfrentados pelos agricultores familiares para permanecerem no programa do biodiesel e conquistarem a titularidade das terras prometidas pelo Governo do Estado do Piauí?A partir da experiência do NPSC é possível afirmarmos que a inclusão da agricultura familiar no mercado do biodiesel gerou dependência dos agricultores familiares ao agronegócio? As negociações e disputas entre os atores sociais (empresa e agricultores) pelo controle dos recursos utilizados nos processos produtivos de oleaginosas geraram conflitos que contribuíram para o insucesso do projeto produtivo do NPSC, projeto-piloto que seria reaplicado nos demais estados do Brasil pelo programa do biodiesel?

Nosso estudo partiu da hipótese de que, a política de distribuição de terras em troca da exploração da força de trabalho dos agricultores familiares para produção capitalista de "energia verde" no Piauí, acentuou o processo de sujeição da renda da terra ao capital, perda de autonomia e intimidade nos espaços domésticos e expropriação dos saberes agrícolas tradicionais.

Nossa reflexão está dividida em cinco partes, além desta introdução e conclusões. Na primeira, abordamos os percursos metodológicos empreendidos para a realização da coleta de dados que deram origem a esse artigo. Na segunda, contemplamos uma breve exposição sobre a política nacional do programa do biodiesel, bem como, sobre a singularidade desse assentamento, que não está em consonância com o que conceitualmente se entende por assentamentos de reforma agrária no Brasil. Na terceira, analisamos as transformações sociais ocorridas na vida das famílias a partir da discussão de resistências cotidianas (Scott, 2002) no enfrentamento ao modelo de moradia denominado "células de produção" ${ }^{1}$, analisados na perspectiva controle, dominação e poder (Foucault, 1987). Na quarta, abordamos os conflitos gerados pela tentativa de integrar a agricultura de base familiar no mercado do biodiesel pela lógica do agronegócio. Na quinta, analisamos o debate sobre a fragilidade da proposta de 
distribuição de terras associada à produção de matéria-prima para o biodiesel. E, por fim, as conclusões com os principais pontos de conflitos que emergiram dessa proposta de desenvolvimento rural, distribuição de terras e acesso ao mercado do biodiesel, tendo como principal porta de entrada a parceria entre agricultores familiares e agricultura empresarial dos agrocombustíveis.

\section{Procedimentos metodológicos}

A base de dados utilizada para esta reflexão é resultado de aproximadamente 10 anos de estudos sobre os desdobramentos da política pública de produção de biodiesel com a participação da agricultura familiar no fornecimento de matéria-prima para as agroindústrias processadora de agrocombustíveis.

Metodologicamente, para este artigo apresentamos dados levantados em três diferentes momentos. O primeiro ocorreu no ano de 2010, durante a realização do mestrado. Para aquela pesquisa adotamos o método etnográfico para apreender as práticas sociais cotidianas das famílias dos agricultores assentados na condição jurídica de parceiros rurais da usina de biodiesel. Aquele período foi considerado o cume dos principais conflitos entre empresa, agricultores e governo sobre os desencontros do modelo de projeto produtivo implementado. Aquela etapa da pesquisa, com duração de seis meses, possibilitou compreender a natureza dos conflitos que se davam no interior dos grupos sociais, bem como, entender a importância dos laços de solidariedade entre os grupos que vieram da mesma origem geográfica. Com efeito, tais dados contribuíram para lançar luzes sobre as ressignificações dos modos de vida dos agricultores que passavam por profundas transformações sociais num determinado espaço e tempo socialmente construído por uma determinada política pública.

O segundo momento ocorreu no período de 2012 a 2015, na condição de consultora de um projeto de cooperação técnica para o Desenvolvimento Econômico Territorial - DET na região da Serra da Capivara, abrangendo também, as terras do NPSC. No período, levantamos informações que resultaram na organização de um banco de dados para uso de relatórios técnicos e análise da implementação da política pública do biodiesel no estado do Piauí. Foram 18 entrevistas com as lideranças comunitárias das células de produção e coleta de dados qualitativos através da técnica de grupos focais com todos os agricultores assentados.

O terceiro momento ocorreu no ano de 2018, durante a realização da pesquisa para o doutoramento nos estados do Piauí e Bahia, ambos na região Nordeste, e Rio Grande do Sul, região Sul do Brasil. Esses três estados foram selecionados por serem reconhecidos pela importante participação da agricultura familiar no programa do biodiesel, seja como caso de sucesso no Rio Grande doSul, ou fracasso na Bahia e Piaú. 
Apesar do uso de métodos mistos (quantitativo e qualitativo) na pesquisa comparativa durante o doutoramento, para este artigo, contudo, utilizamos apenas os dados qualitativos referentes ao estado do Piauí. A decisão se justifica pelo interesse em analisarmos aqui os desdobramentos do cumprimento da promessa de doação das terras ${ }^{2}$ do NPSC para os agricultores parceiros que permanecessem produzindo oleaginosa para o biodiesel por no mínimo dez anos.

Para a compreensão da realidade social dos agricultores familiares que permaneceram no NPSC, realizamos 10 entrevistas semiestruturadas com os agentes estatais, agentes privados e atores das organizações sociais ligados à agricultura familiar e que estiveram no centro do debate sobre os resultados alcançados pela implementação do programa do biodiesel no estado do Piauí. Além das entrevistas, o campo também proporcionou a construção de um diário de campo, técnica de pesquisa que se mostrou importante para a análise dos processos sociais dos discursos dos sujeitos pesquisados.

Na análise de conteúdo das entrevistas realizadas com os agricultores, valorizamos apreender os sentidos atribuídos através de suas práticas discursivas sobre as relações sociais que se estabeleceram no NPSC. Esse olhar para o interior das práticas, de acordo com Spink e Lima (2000), contribui para o rigor na explicitação e interpretação das práticas, meio a suas subjetividades e circularidades.

\section{O programa do biodiesel e a agricultura familiar: Desafios para o alcance da dimensão social do programa no Piauí}

O Brasil tem despontado no mercado internacional como referência na produção de agrocombustíveis, particularmente, nos últimos 30 anos. O etanol de cana-de-açúcar produzido no Brasil, por exemplo, é considerado um biocombustível avançado no que diz respeito ao uso de tecnologias sustentáveis e investimentos em pesquisas. Mas na dimensão social, o PROÁLCOOL não conseguiu incluir os agricultores pobres $^{3}$ na cadeia produtiva desse agrocombustível. Pelo contrário, a participação da agricultura familiar brasileira se deu na condição de boias-frias, ${ }^{4}$ com a exploração de mão-de-obra e precarização do trabalho (Wanderley, 1998).

OPNPB, lançado em 2004, nasceu com a ideia de investir em alternativas para a substituição de combustíveis derivados do petróleo, desenvolver fontes de energia menos agressivas ao meio ambiente e promover o desenvolvimento da agricultura familiar, particularmente nas regiões Norte e Nordeste.

O PNPB está sustentado por quatro forças motrizes: 1) a redução da importação de petróleo e derivados, o que é tanto econômica quanto geopoliticamente estratégico; 2) a mitigação das mudanças climáticas e a redução das emissões 
poluentes causadas pela combustão de óleo diesel; 3) a expansão agrícola; e 4) a inclusão social (Instrução Normativa $n^{0}$ 02, 2005).Contudo, nesta pesquisa adentrou-se na compreensão do conjunto de estratégias para o alcance da dimensão social do programa do biodiesel, por ser este o objetivo mais propalado pelos agentes formuladores e implementadores da referida política pública.

A regulamentação do PNPB representou um marco nas políticas de produção de biocombustíveis no Brasil, uma vez que a formulação da política já previa a participação de um segmento importante da agricultura no Brasil que, de certa maneira, sempre foi negligenciado pelas políticas públicas rurais. Para a sua implementação, houve um esforço do Governo para mobilizar parcerias entre as indústrias processadoras do biodiesel e os agricultores familiares, visando atender os percentuais de uso compulsório do biodiesel na matriz energética brasileira. Este empenho governamental se fez necessário porque o mote de sensibilização para a aprovação do PNPB foi de que se tratava de uma política energética com dimensão social, uma vez que, ao incluir os agricultores familiares pobres, sobretudo aqueles oriundos das regiões Norte e no Nordeste do Brasil, estaria de fato cumprindo com a promoção do desenvolvimento rural através da geração de emprego e renda.

Como estratégia para a implementação da dimensão social do programa, o Governo Federal criou um instrumento legal denominado Selo Combustível Social (SCS), que permitiu às empresas do setor dos agrocombustíveis obterem o benefício da redução de impostos federais, condições mais vantajosas para o financiamento de projetos junto ao Banco Nacional de Desenvolvimento Social - BNDES, dentre outras vantagens, quando comprovada a inclusão da agricultura familiar no mercado do biodiesel.

A proposta da política nacional de produção do biodiesel no Brasil vai além das preocupações com a mitigação dos efeitos poluentes no ar. Para Abramovay (2009), representa um avanço nas políticas públicas voltadas para a agricultura familiar. Uma das expectativas com a implementação do SCS seria evitar com que o mercado do biodiesel fosse dominado pela produção de soja e pelas agroindústrias.

O Selo Combustível Social (SCS) era concedido pelo extinto Ministério do Desenvolvimento Agrário - MDA até o ano de 2018 e, atualmente, concedido pela Secretaria da Agricultura Familiar e Cooperativismo SEF/MAPA, a unidade industrial produtora de biodiesel que cumpre os critérios descritos nas suas normativas sobre $\mathrm{o}$ tema ${ }^{5}$, e que confere ao seu possuidor o caráter de promotor de inclusão social dos agricultores familiares enquadrados no Programa Nacional de Fortalecimento da Agricultura Familiar - PRONAF, uma política pública criada em 1996 com o objetivo de estimular a expansão da agricultura familiar no País e que atualmente está presente em todos os municípios brasileiros (Instrução Normativa $\left.n^{\circ} 02,2005\right)$. 
Para efeito de acesso à política do biodiesel são reconhecidos como agricultores familiares aqueles que praticam atividades no meio rural, atendendo, simultaneamente, aos seguintes requisitos:

a- não detenha, a qualquer título, área maior do que 4 (quatro) módulos fiscais 6 ; b- utilize predominantemente mão-de-obra da própria família nas atividades econômicas do seu estabelecimento ou empreendimento; c- tenha renda familiar econômica do seu estabelecimento ou empreendimento na forma definida pelo Poder Executivo; d- dirija seu estabelecimento ou empreendimento com sua família (Silva, 2019, p. 31).

Em 2006, o Brasil deu um passo significativo com o reconhecimento da agricultura familiar como segmento produtivo com a aprovação da lei $n^{\circ} 11.326$, de 24 de julho de 2006. A lei estabelece os conceitos, princípios e instrumentos destinados à formulação das políticas públicas direcionadas à Agricultura Familiar e Empreendimentos Familiares Rurais (Portaria $n^{\circ}$ 4, 2016). Para a referida lei, os agricultores considerados familiares precisam receber de órgão competente um documento ${ }^{7}$ que lhes confere o reconhecimento jurídico da categoria para fins de acesso a políticas públicas destinadas a esse segmento. A lei consolidou institucionalmente o programa, fazendo da existência de políticas específicas para a agricultura familiar um caminho sem volta (Mattei, 2010, p. 7).

Como contrapartida destes benefícios concedidos pelo Governo através do SCS, os proprietários das usinas assumem a obrigação de celebrar previamente contratos de compra e venda de matérias-primas com os agricultores familiares enquadrados no PRONAF, ou com suas cooperativas e com anuência de entidade representativa da agricultura familiar; assegurar capacitação e assistência técnica gratuita aos agricultores com contratos; e adquirir um percentual mínimo de matéria-prima destes para produção de biodiesel.

A produção de agrocombustível no Brasil despontou como uma importante estratégia de reserva demercado para as agroindústrias, principalmente, aquelas com comprovada influência junto ao Governo. A conquista do SCS facilita a participação das usinas em leilões em condições diferenciadas, se comparadas com as demais usinas concorrentes que não usufruem do Selo. Entre 2006 e 2016, o número de usinas produtores de biodiesel subiu de 02 para 61. E dessas, 41 encontram-se em operações comerciais com a Petrobrás Biocombustíveis (Portaria $n^{\circ} 4$, 2016). A empresa instalada no Piauí foi pioneira no programa na participação de leilões prioritários para as empresas detentoras do SCS.

O Governo do Estado do Piauí regulamentou, por meio da Lei Estadual 5.333/2003, a doação de 36 mil hectares para fins de "reforma agrária privada", utilizando-se de recursos da iniciativa privada. Na Figura 1 é possível visualizar a 


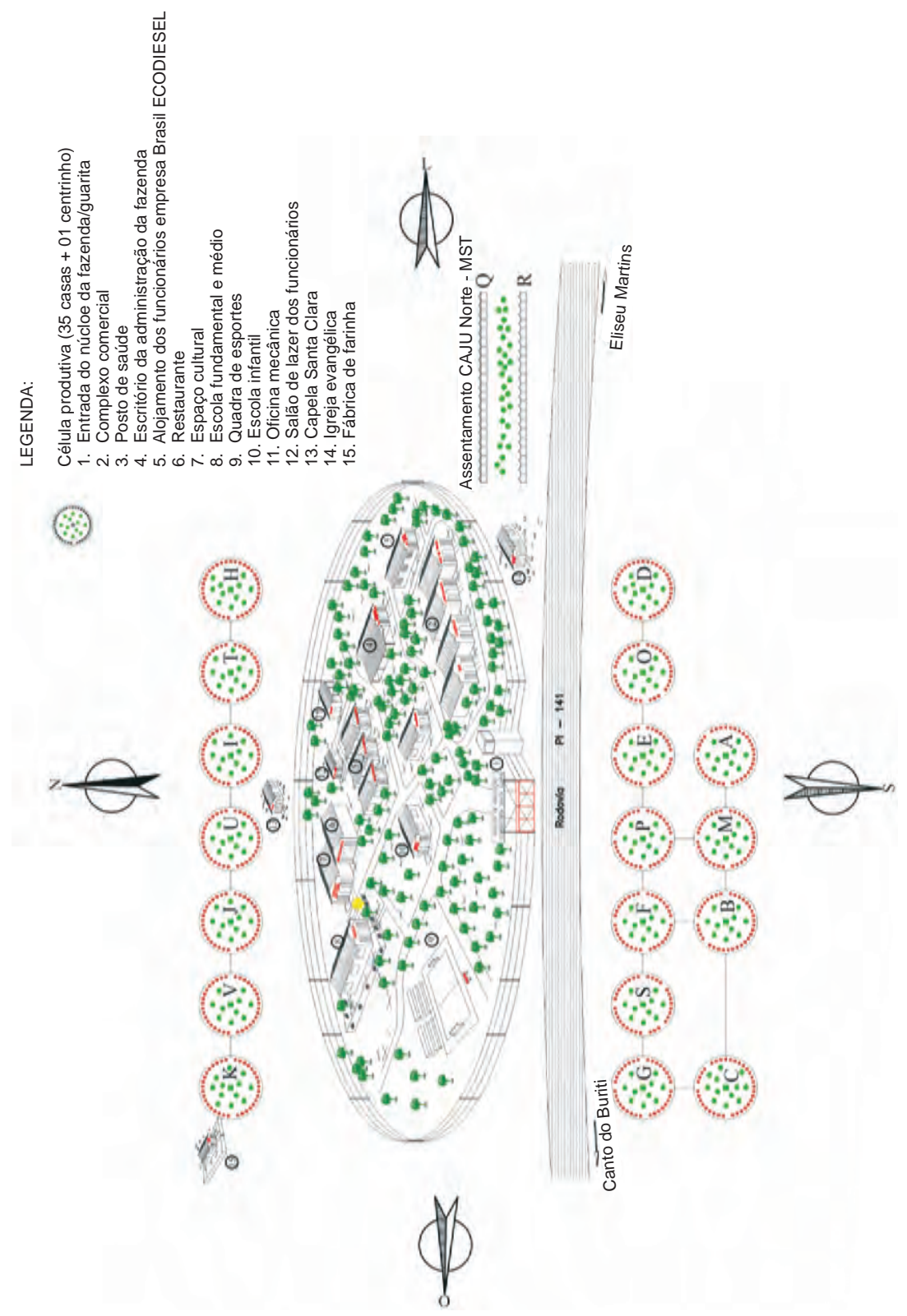

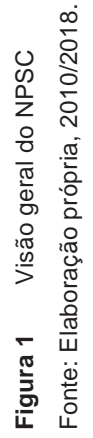


infraestrutura construída pelos investidores de agrocombustíveis nas terras disponibilizadas pelo Estado para o funcionamento do projeto produtivo. Essa ilustração trata-se de um mapa etnográfico com a visão geral do NPSC elaborado no ano de 2010 e atualizado no ano de 2018 para melhor compressão sobre a dinâmica espacial das moradias e das áreas de uso comum com a oferta dos serviços de saúde, educação e assistência produtiva no NPSC.

A proposta de funcionamento do projeto de produção de mamona para a extração do biodiesel dependia exclusivamente da força de trabalho das famílias assentadas na condição de parceiros rurais. Em troca, ao término do contrato com vigência de dez anos, as famílias receberiam da empresa a titularidade correspondente a vinte e cinco hectares das terras prometidas ${ }^{8}$ no ano de 2014.

A parceria entre empresa e agricultores foi regulamentada pelo Contrato de Parceria Rural Agrícola, baseado na Lei de $\mathrm{n}^{\circ}$ 4.504, de 30 de novembro de 1964, e pelo Decreto n ${ }^{\circ} 59.566$, de 14 de novembro de 1966 - o Estatuto da Terra. Nessa parceria, a nova posição social do agricultor parceiro não é a de assentado, pois ele não possui o reconhecimento da política de assentamento rural, nem é a de proprietário, porque não possui a titularidade dos lotes. A configuração de parceria rural originou novos desdobramentos na forma como esses agricultores passaram a se relacionar com o mercado, com a agroindústria e, sobretudo, com a produção em grande escala. Essa nova condição representou a perda da autonomia produtiva em relação ao que cultivar e comercializar, bem como o abandono de práticas adquiridas ao longo das suas gerações. A organização social manteve-se fundada no trabalho familiar, mas este deixou de ter um caráter local, de subsistência com comercialização do excedente, para inserir-se na produção voltada ao mercado de combustível.

À luz destas observações, foi possível inferirmos que a parceria rural estabelecida no âmbito do NPSC está longe da situação clássica estudada por Antônio Cândido (1987) no livro "Os Parceiros do Rio Bonito", que, em linhas gerais, apresenta uma parceria de arrendamento, unindo parceiros e proprietários, num universo social em que as distâncias sociais e as distorções na gestão dos negócios são relativamente pequenas. Identificamos que a relação de parceria rural era um dos pontos conflitantes entre os agentes envolvidos pela incompatibilidade de interesses: de um lado o agronegócio demandando escalas de produção acima da capacidade da mão de obra dos agricultores parceiros, e do outro, os agricultores tensionando constantemente os formatos de relações de poder com extensionistas rurais, recusando-se a colocar em prática um calendário agrícola voltado exclusivamente para o mercado.

As expectativas das entidades governamentais e agroindústria envolvida na parceria com o NPSC eram de que a produção de matéria-prima com o uso da mão de obra familiar conseguisse atender toda a demanda da refinaria, ${ }^{9}$ instalada com o 
uso de $40 \%$ dos recursos públicos no município de Floriano, Piauí. No entanto, tais expectativas foram frustradas, não apenas pela baixa produtividade da oleaginosa escolhida, mas também pela própria resistência dos agricultores em se dedicarem a cultivos não comestíveis. Sabe-se que para manter o interesse dos investidores dos agrocombustíveis em determinada parceria é preciso que eles tenham lucros. O não alcance da escala de produção necessária à manutenção das suas refinarias aumentou as tensões entre agricultores parceiros e a Agroindústria.

A busca por novas energias acabou se transformando numa atividade muito rentável para os investimentos do grande capital (Houtart, 2010). O Brasil é um dos maiores produtores da agroenergia, com expressivos resultados na produção de etanol. Todavia, foi somente com o biodiesel que se pensou uma estratégia de mercado para um biocombustível com capacidade de incluir agricultores familiares e pobres excluídos da cadeia produtiva do etanol.

Em suma, o quesito dimensão social da política pública do biodiesel com a inclusão da agricultura familiar no NPSC foi marcado por constantes tensões e conflitos gerados a partir da tentativa de articulação de dois segmentos historicamente antagônicos na pirâmide da agricultura brasileira - o agronegócio e a agricultura de familiar. Os agricultores assentados na condição de parceiros rurais sempre estiveram à margem das ações do Estado. Ademais, quando o poder público estatal os convoca para incrementar um projeto produtivo que se propõe a distribuir terras ao final do contrato, esses agricultores enxergam ali a possibilidade de acesso à terra como proprietários para viabilizar a reprodução social do grupo familiar, conforme será discutido nos próximos tópicos.

\section{Organização espacial circular: Uma estratégia disciplinar dos agricultores em suas moradias no NPSC?}

A moradia assume múltiplos significados na reprodução social dos grupos sociais. De acordo com Brosler e Bergamasco (2016), a casa camponesa é o lugar que se tem para voltar, sendo ela uma "entidade" que organiza, centraliza e distingue as famílias e seus modos e estilos de vida. A moradia tem sido elemento de resistências e lutas de grupos organizados ou não em movimentos sociais, sindicatos e associações. A trajetória social dos agricultores que se deslocaram para o NPSC é marcada pela expropriação das suas terras, pelo avanço do agronegócio, do Estado e pela expulsão das terras dos patrões quando viviam na condição de sitiantes, moradores ou meeiros.

As famílias de agricultores parceiros no NPSC foram assentadas em espaços que receberam o nome de "célula de produção" devido a sua configuração espacial no formato circular. Em cada círculo foram construídas trinta e cinco casas que 


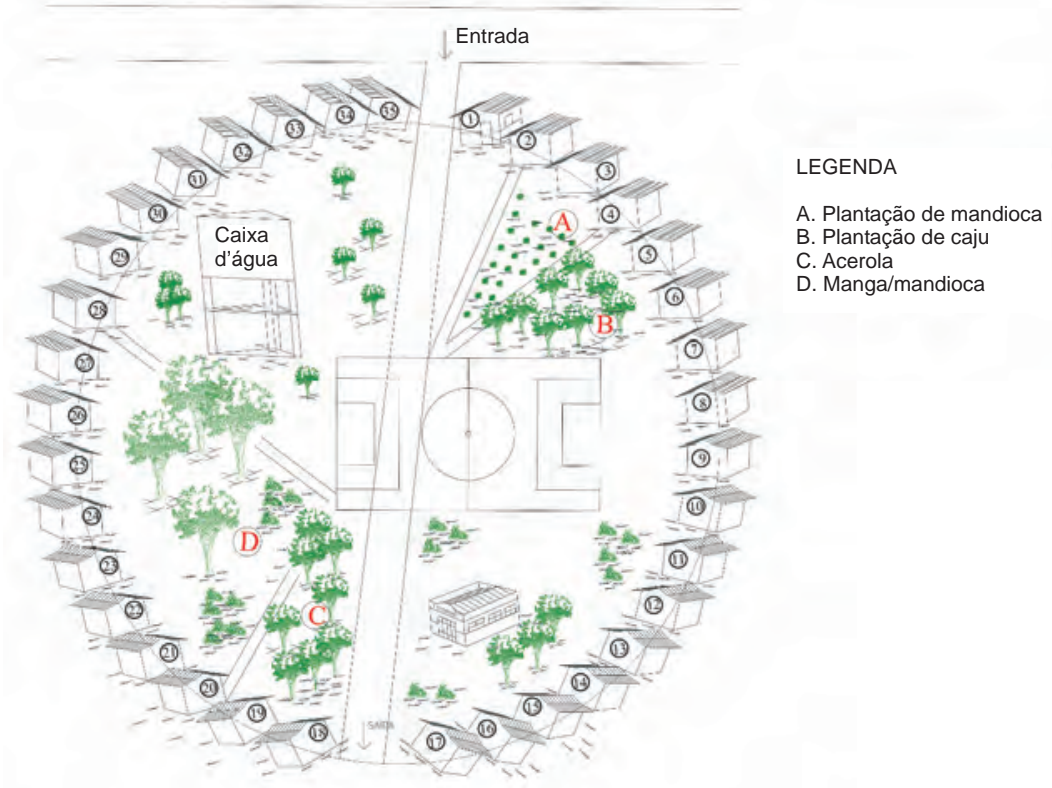

Figura 2 Célula de produção e moradia

Fonte: Elaboração da autora, 2010/2018.

obedeceram também à disposição circular e um espaço de uso coletivo no centro de cada célula, conforme um mapa etnográfico elaborado no ano de 2010 (figura 2), sem necessidade de revisão porque as casas continuam dispostas da mesma forma. No ano de 2018, observamos que algumas casas passaram por reformas, melhorias ou, em outros casos, se deterioraram ao serem abandonadas pelas famílias, que migraram para a cidade em busca de melhores condições de vida.

Adaptar-se ao novo formato da moradia foi o primeiro desafio enfrentado pelos agricultores quando chegaram ao NPSC. O modelo adotado pela empresa possibilitava que todas as casas fossem visualizadas simultaneamente, o que favorecia o controle do tempo de dedicação dos agricultores aos cultivos de mamona da empresa.

É importante mencionar que nos três primeiros anos de funcionamento do NPSC, a empresa adotou um modelo de gestão que ficou marcada pelo autoritarismo e com ocorrência de violência física, psicológica e até mesmo a expulsão de famílias que não se adaptaram à vida no NPSC. E dentre essas adaptações estava à proibição de alterarem a estrutura física da casa e seu entorno.

A proibição da alteração do espaço físico das moradias representava para a empresa a manutenção da sua autoridade sobre as famílias e, em sua concepção, a 
violação das regras estabelecidas no contrato de parceria representava uma ameaça à ordem e a seu poder e controle dos "dóceis corpos" dos agricultores (Foucault, 1987).

As tentativas de interferências no desenho original das moradias por parte dos agricultores corroboram com o que Scott (2002) denominou por "formas cotidianas de resistência". As resistências que ali emergiram, fossem elas coletivas ou individuais, foram particularmente importantes no enfrentamento às ameaças de descontinuidade dos seus modos de vida pela de autonomia e aumento da dependência do agronegócio.

Ainda sobre os aspectos de poder e controle do comportamento dos agricultores através da vigilância constante e da punição dos que subvertiam as regras da empresa, poderíamos pensar na contribuição teórica de Foucault (1987), que ao estudar a sociedade disciplinar, constata que a sua singularidade reside na existência do desvio diante da norma. E assim, para "normalizar" o sujeito moderno, foram desenvolvidos mecanismos e dispositivos de vigilância capazes de interiorizar a culpa e causar remorsos pelos seus atos.

Ao analisarmos a organização espacial das moradias no NPSC é possível realizarmos generalizações a partir dos modelos disciplinares desenvolvidos por Foucault (1987), quando este ampliou a compreensão do conceito de panóptico cunhado por Jeremy Bentham. Da entrada principal da célula, os técnicos da empresa visualizavam simultaneamente o interior de todas as casas sem que os agricultores os vissem. Essa estratégia de "ver sem ser visto" favorecia o controle sobre aqueles agricultores que não iam para a roça como forma de protesto.

A observação constante dos agricultores a partir do modelo de moradia circular, segundo Foucault (1987), condicionava o comportamento daqueles observados. Para o autor, essa sensação de constante vigilância tem a intenção de condicionar o sujeito a comportamentos sociais adequados, ou de acordo com as normas estabelecidas. Contudo, quando essa vigilância não atinge o objetivo de controlar comportamentos de cunho coercitivo e disciplinatório, os mecanismos se asseveraram, punindo-os.

Ademais, quando questionado sobre o modelo de moradia adotado por um projeto que se propunha a ser referência no alcance da dimensão social do programa do biodiesel com a geração de renda e melhorias nas condições de vida daqueles agricultores sem-terra, um representante oficial da empresa negou qualquer associação do modelo arquitetônico por eles adotado com panóptico. Mas reconheceu que o fato das casas estarem em disposição circular facilitava o trabalho dos técnicos agrícolas, uma vez que conseguiam visualizar, ao mesmo tempo, a porta principal de todas as casas da célula monitorada, que confirmou a intencionalidade por parte da empresa em controlar todos os movimentos dos agricultores, dentro e fora da roça.

Como enfretamento ao controle, os agricultores passaram a plantar árvores de grande porte na frente das suas casas como estratégia para mantê-los distantes 
dos olharesde controle da empresa, situaçãonarrada pelo agricultor:

As plantas na frente das casas não serviam apenas para proteger a nossa intimidade, sabe. A gente fazia isso para não ser avistado pelos meninos [extensionistas rurais] e nem pelos vizinhos que iam contar para o gerente que neguinho [agricultor] passou o dia todo dentro de casa e não quis ir para a roça cuidar da mamona. A gente fingia que estava tudo bem, que estava aceitando, para ganhar tempo e mudar (C. S, 52 anos).

Os agricultores lutaram insistentemente contra o autoritarismo da empresa através da resistência cotidiana pela manipulação das relações de poder sobre quem manda e quem obedece, conquistando pequenos ganhos (Scott, 2002).

É fato que, diante da perda de autonomia em decorrênciada relação comercial deuso das terras para a produção capitalista, amoradiarepresenta, para os agricultores, o único espaço em que continuavam exercendoo podere controle. A luta pelo controle e exercício da autoridade no espaço doméstico pode ser analisada como uma espécie de reparação, ou seja, o agricultor precisava compensar a perda da autonomia na roça pela retomada do controle sobre a moradia. Ao assinarem o contrato de parceria rural, os agricultores perderam total autonomia sobre a decisão dos cultivos e permissão para a criação de pequenos animais (aves, caprinos, bovino, suínos etc.), conforme exposto nos tópicos seguintes.

\section{A produção de base familiar em parceria com o agronegócio: uma relação permeada por conflitos no NPSC}

No Brasil, a produção de energias renováveis pelo agronegócio tem demonstrado a relevância dos impactos sociais e culturais ocasionados pela substituição de cultivos alimentares tradicionais por monoculturas dependentes de pesticidas e fertilizantes, provocando danos à saúde humana e degradação ambiental (Barbosa \& Jordão, 2015). Com efeito, a expansão capitalista da produção de agrocombustíveis não ocorre sem pressão sobre os ecossistemas e seus povos. Para Houtart (2010), como sempre, em um projeto capitalista, ignora-se o que os economistas chamam de externalidades, isto é, o que não entra no cálculo do mercado; os danos ecológicos e sociais.

Para atender a crescente demanda por matéria - prima para a produção de agrocombustíveis, os países em desenvolvimento estão implementando políticas públicas concedendo a exploração comercial em milhões de hectares de terras agricultáveis para o agronegócio. A expansão agrocombustíveis nesses países tem provocado a expulsão de, pelo menos 60 milhões de camponeses das suas terras. O preço dessas "externalidades", não pago pelo capital, mas pela comunidade e pelos indivíduos na produção de agroenergia é espantoso (Houtart, 2010, p. 52). 
As relações de conflito no NPSC se intensificaram quando os agricultores tomaram consciência de que o modelo de produção capitalista seria adotado pela agroindústria do biodiesel parceira. E que essa era condição sine qua non para suas permanências e, conseguintemente, terem acesso à titularidade das terras, conforme contrato de parceria firmada entre empresa, governo e agricultor.

Nos aspectos produtivos, a empresa de biodiesel, além de não reconhecer a importância dos cultivos alimentares praticados tradicionalmente pelos agricultores, também desconsiderou as vivências e interações destes com os mercados locais. Ir à feira livre, semanalmente, comercializar pequenas quantidades de legumes e/ou animais era uma prática social que estava além das relações meramente mercantis. Com efeito, toda a produção de mamona era repassada para uma única agroindústria e os alimentos deixaram de ser cultivados para serem comprados, assumindo, assim, uma relação de total dependência externa de tudo que consumiam.

Tradicionalmente, os agricultores estavam habituados a cultivar pequenas áreas de, no máximo, 02 (dois) hectares. $\mathrm{O}$ tempo dedicado a 8 (oito) hectares da agroindústria com monocultivos de mamona inviabilizou a produção de alimentos para o autoconsumo. Toda a mão de obra disponível na familiar foi destinada para a produção comercial. A tomada de consciência dos agricultores sobre a exploração das suas forças de trabalho resultou em protestos com a interdição da rodovia que dá acesso à capital do estado do Piauí, chamando a atenção dos órgãos de fiscalização do Ministério do Trabalho. Este último interveio nas irregularidades denunciadas, diminuindo, inclusive, o tamanho da área de cultivos de mamona exigido a cada família para terem acesso à titularidade da terra. Contudo, essa redução não garantiu o sucesso do programa do biodiesel no NPSC porque que os agricultores também resistiam a empregar toda a mão de obra familiar em único cultivo.

A articulação entre produção de base familiar e a capitalista no âmbito do programa do biodiesel no Piaú demonstrou inexpressivos resultados na proposta de inclusão dos segmentos mais vulneráveis da agricultura no mercado do biodiesel. A relação de parceria rural estabelecida retirou dos agricultores a autonomia sobre o que produzir, rompendo bruscamente com práticas e saberes tradicionais. Para Woortmann, Suárez e Veloso (1983, p.152), a reprodução dos camponeses no campo depende das experiências e saber que lhes é próprio. A reprodução dessas relações de produção depende da operacionalização do saber que rege o processo de trabalho, ao mesmo tempo em que são elas próprias a condição para essa operacionalização. De tal modo que, os conflitos suscitados pela adaptação as novas práticas sociais por parte dos agricultores transformaram o NPSC num espaço de constantes conflitos e resistências (Scott, 2002). Tal negação deflagrou, dentro dos grupos, resistência ao cultivo da mamona, bem como estratégias cotidianas para a retomada da autonomia que 
perderam ao se tornarem parceiros rurais. Para Scott (2002), naquelas experiências cujos camponeses se encontram em uma situação-limite de controle, as estratégias na busca de espaços de autonomia nos processos produtivos tornam-se uma constante no cotidiano das famílias.

No Piauí, a experiência de produção da agroenergia associando a agricultura familiar e o agronegócio contribuiu para a redução dos repertórios de aplicação do conhecimento tradicional na roça, em especial aquele direcionado para a produção de alimentos habitualmente praticada. Woortmann, Suárez e Veloso (1983) demonstraram que experiências de desenvolvimento da agroindústria com a valorização das terras provocaram mudanças no tradicional processo de trabalho e modos de vida dos agricultores implicados diretamente nesse processo de sujeição da renda da terra ao capital.

\section{A luta pela conquista da terra prometida no NPSC}

No Piauí, a política de distribuição de terras e regularização fundiária ainda é um desafio a ser superado na estrutura fundiária do Estado e que está aquém de uma solução a curto ou médio prazo. As terras agricultáveis estão concentradas nas mãos da minoria produtora de commodities e, mais recentemente, em meio a disputas por terras agricultáveis pela extrangeirização de terras. Apesar de se tratarde um Estado em que sua base econômica está ancorada na agricultura de pequeno porte, estes não são alvos das políticas públicas de incentivo à manutenção das suas atividades no campo. As ações do Estado para o fortalecimento da agricultura de base familiar, além de incipientes, são baseadas em modelos desenvolvimentistas, contribuindo, assim, para o aprofundamento das desigualdades sociais produzidas pela expropriação de terras camponesas em favor do agronegócio.

O Governo do Estado do Piauí doou através da Lei Estadual no 5.333/2003, uma área de 36 mil hectares de terras agricultáveis para a iniciativa privada assentar 639 famílias de agricultores familiares sem-terra na condição jurídica de parceiros rurais da agroindústria processadora de biodiesel. A condição para o acesso à titularidade dos lotes do NPSC era que os agricultores permanecessem fornecendo matéria prima para a agroindústria parceira por no mínimo dez anos, a contar do contrato de parceria rural firmado no ano de 2004.

Após o término do contrato de parceria rural, a agroindústria do biodiesel encerrou suas atividades no estado do Piauí e não cumpriu com sua obrigação de repassar os títulos de propriedade dos lotes do NPSC sem ônus para o Estado e nem para os agricultores. Tal falha na parceria rural levou ao agravamento da situação de vulnerabilidade social, econômica e fundiária dos agricultores parceiros. Afinal, já 
se passaram dezesseis anos desde a chegada dos agricultores nas terras do NPSC e a regularização fundiária dos lotes ainda não aconteceu.

No ano de 2017, o Estado declarou para as famílias que 21 mil hectares do NPSC encontravam-se certificados no Instituto Nacional de Colonização e Reforma Agrária-INCRA, resultante da grilagem ${ }^{10}$ de terras no Piauí. De acordo com a assessoria do Instituto de Terras do Piauí - INTERPI foi solicitado no final do ano de 2018 o cancelamento da certificação irregular dessas terras para fins de reforma agrária, contemplando as famílias que continuaram no NPSC. O gestor de terras do INTERPI informou que, dada a complexidade do fenômeno da grilagem de terras, tudo leva a crer que tal cancelamento da certificação levará décadas para ser solucionado.

No ano de 2018, os agricultores do NPSC ocuparam o INTERPI para pressionar o governo estadual pela celeridade no cumprimento da regularização fundiária das terras do assentamento. O protesto foi passivo e contou com o apoio das entidades representativas da luta pela terra e da agricultura familiar camponesa. As lideranças das células foram recebidas pela comissão estatal de regularização fundiária, mas sem soluções concretas por parte do Estado. Sem resposta e com dificuldades para permanecerem nas terras do NPSC, em outubro de 2019 os agricultores, agora representados pela Associação Comunitária dos Moradores da Santa Clara, se reuniram com os representantes do INTERPI para exigir que o governo iniciasse o processo de regularização fundiária das 15 mil hectares que se encontram sem restrição cadastral para a titularização.

Sem condições financeiras para a permanência nas terras do NPSC, a migração temporária voltou a fazer parte do repertório das estratégias de reprodução social das famílias. Tem sido comum, no período da entressafra, os chefes das famílias migrarem para realizar trabalhos agrícolas na condição de temporários em outros estados no Brasil.

Observamos também que outros deslocamentos vêm ocorrendo pela procura de escolas para os filhos. Ao serem questionadas, as famílias alegaram que estão enviando os filhos em idade escolar aos cuidados dos parentes nos centros urbanos mais próximos porque a escola que se mantém ativa no NPSC vem funcionando em condições precárias. Esse relato foi comprovado durante a pesquisa de campo realizada em 2018, em que nos deparamos com uma unidade escolar (ver Figura 3) funcionando sem água para o consumo dos alunos, salas desativadas porque o teto havia desabado no início do ano letivo, não havia transporte escolar para o deslocamento das crianças que moravam nas células mais distantes, nem tampouco calendário de aulas regulares, ocasionado pelo número insuficiente de professores. Enfim, observamos o reflexo da ausência de políticas públicas do Estado e do Município no NPSC.

Para as famílias, a convivência com tantas precariedades ao mesmo tempo não tem sido fácil. A ausência da regularidade fundiária traz a invisibilidade dos 


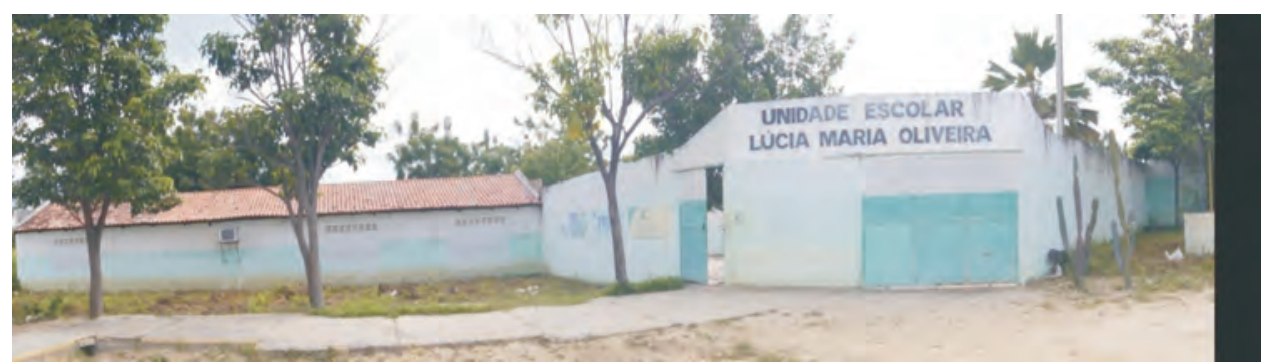

Figura 3 Unidade Escolar em atividade no NPSC

Fonte: pesquisa de campo, 2018.

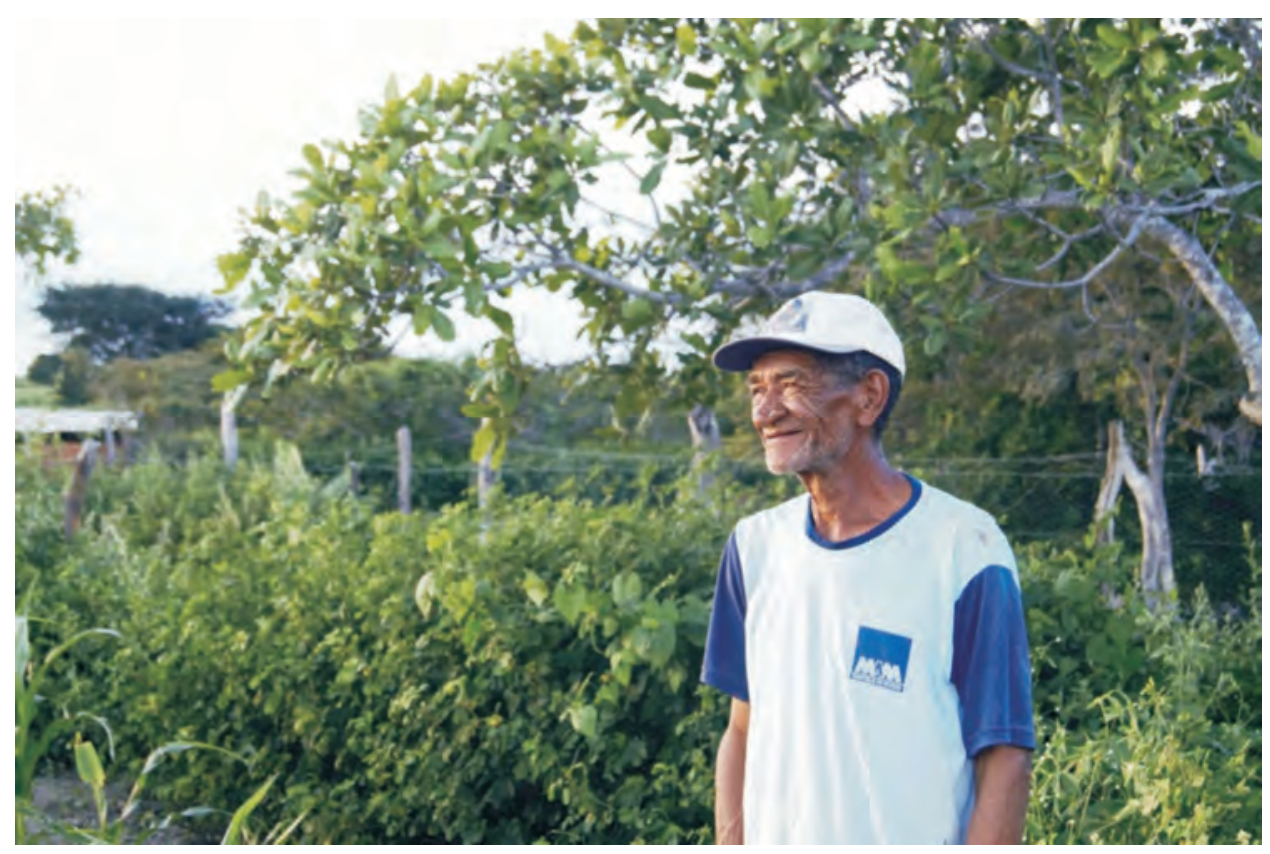

Figura 4 Agricultor que permanece nas terras do NPSC lutando pela regularização fundiária Fonte: pesquisa de campo, 2018. 
agricultores para o acesso a políticas de crédito para o fomento da agricultura familiar, dentre outros. A família do agricultor Souza (Figura 4), de 60 anos, foi a primeira a chegar ao NPSC juntamente com uma irmã e um irmão. Porém, diante das atuais dificuldades, muitas famílias abandonaram suas casas, dentre elas os irmãos do Sr. Souza, que persiste porque, em suas próprias palavras, "receber o título da minha área será uma questão de honra e é a única coisa que posso deixar para meus filhos".

Por fim, o NPSC representa o retrato de um velho modelo de desenvolvimento travestido de moderno, conduzido pelo interesse dos negócios fundiários em terras de importante valor comercial e que têm sido alvo de especulações fundiárias e grilagem de terras no Piauí. O desafio para a resolução do impassede conflito fundiário nas terras da NPSC vai precisar superar alógica que coloca em primeiro lugar osinteresses do capital agrário em detrimento do bem-estar social dos agricultores mais vulneráveis.

\section{Considerações finais}

O estudo demonstrou que a proposta de assentar famílias de agricultores sem-terra para cultivarem oleaginosa para a produção de biodiesel no Piauí desencadeou inúmeros conflitos entre os modos de produção familiar e o agronegócio. Ao desconsiderar a importância dos saberes locais e as experiências adquiridas pelos agricultores antes dos seus deslocamentos para o NPSC, estavam atestando a incapacidade de conciliação das expectativas dos investidores no mercado dos agrocombustíveis com as dos agricultores que cultivavam para a subsistência.

É possível inferir que ocorreu uma espécie de continuum na relação dos agricultores parceiros com a terra do NPSC, ou seja, eles saíram da condição de arrendatários ou moradores num processo de sujeição e subordinação ao proprietário da terra para a condição de parceiros rurais do agronegócio, submetidos a novas regras da produtividade, do mercado e das forças capitalistas agrárias.

Dentre as dificuldades enfrentadas pelos agricultores, consideramos como mais expressiva a não adaptação ao calendário agrícola da agroindústria, porque tiveram de abandonar suas culturas produtivas tradicionais para produzir uma cultura não alimentar, que colocava em risco a reprodução social dos grupos domésticos. Os agricultores lutaram para terem o direito de cultivar para a subsistência da família e comercializar o excedente, mas dentro da lógica de uma economia moral que valorizasse suas próprias escolhas, e não a do agronegócio.

Por fim, essa experiência do NPSC no semiárido do Piauí demonstrou que produzir mamona a partir da agricultura de base familiar para atender a uma demanda específica do agronegócio dos biocombustíveis provocou alterações significativas na relação dessas famílias com o trabalho, a produção, a alimentação, o mercado e o 
acesso à terra. Assim, entende-se a necessidade de reflexões contínuas à luz das atuais políticas públicas de inclusão socioprodutiva e distribuição de terras que submetem o homem do campo a projetos de desenvolvimento rural baseado na economia de mercado regido pelo capital agroindustrial, como a dos agrocombustíveis. A omissão do Estado na regularização das terras em que foram assentadas centenas de famílias de agricultores pobres e sem terras demonstra o quão seletivas são as decisões políticas agrícolas no que se refere às questões sociais e agrárias no Brasil.

\section{Notas}

Por decisão pessoal, a autora escreveu o referido artigo segundo o novo acordo ortográfico.

1 Termo utilizado pela parceira para designar o espaço de moradia e lotes de produção do NPSC.

2 A doação de terras foi considerada uma das singularidades da proposta do Governo do Estado do Piauí para atingir a dimensão social do programa do biodiesel no Estado.

3 Para o PNPB, agricultores pobres são aqueles que possuem renda de até $1 / 2$ salário mínimo (dimensão econômica).

4 Trabalhador rural itinerante que se ocupa em tarefas temporárias sem vínculos empregatícios.

5 Atualmente, a norma que estabelece regras para concessão, manutenção, renovação e cancelamento do Selo Combustível Social é a Instrução Normativa do MDA n 01 de 19 de fevereiro de 2019.

6 É uma unidade de medida agrária expressa em hectares definida para cada município, dependendo do sistema de produção predominante. A depender do município, 1 Módulo Fiscal varia de 5 a 110 hectares.

7 Declaração de Aptidão para a Agricultura - DAP.

8 A terra prometida, termo que tomo emprestado das narrativas dos informantes ao se referirem à situação de promessa de vinte e cinco hectares a cada família assentada ao término do contrato de parceria rural.

9 No ano de 2019, o Governo do Estado do Piauí anunciou que aportarão recursos no montante de 60 milhões para reativar essa usina de biodiesel, sem mencionar as medidas sobre a regularização fundiária das terras do NPSC.

10 No Brasil, grilagem de terras é a falsificação de documentos para, ilegalmente, tomar posse de terras devolutas ou de terceiros.

\section{Referências}

Abramovay, R. (Org.). (2009). Biocombustíveis - A energia da controvérsia. São Paulo: Editora Senac.

Barbosa, C. V., \& Jordão, L. R. (2015). A produção de agrocombustíveis e o enlaço com a segurança e soberania alimentar. Revista de Direito Agrário e Agroambiental, 1(2), 139-164. 
Brosler, T. M., \& Bergamasco, S. M. P. P. (2016). A conquista do direito à moradia no meio rural; proposta de construção de um indicador. Paranoá: Cadernos de Arquitetura e Urbanismo, (17). doi: 10.18830/issn.1679-0944.n17.2016.05. Disponível em http:/ / periodicos.unb.br/index.php/paranoa/article/ view/24746/17988

Cândido, A. (1987). Parceiros do Rio Bonito: Estudo sobre o caipira paulista e a transformação dos meios de vida. São Paulo.

Foucault, M. (1987). Vigiar e punir: História da violência nas prisões. Petrópolis: Vozes.

Houtart, F. (2010). A agroenergia: Solução para o clima ou saída da crise para o capital?. Petrópolis: Vozes.

Instrução Normativa $n^{\circ}$ 02, de 30 de setembro de 2005. Dispõe sobre os critérios e procedimentos relativos ao enquadramento de projetos de produção de biodiesel ao selo combustível social. MDA - Ministério do Desenvolvimento Agrário. Disponível em http://www.mda.gov.br/sitemda/sites/sitemda/ files/user_arquivos_627/IN\%2002\%20-\%202005\%20MDA.pdf

Mattei, L. (2010). Programa Nacional para Produção e uso do Biodiesel no Brasil (PNPB): Trajetória, situação atual e desafios. Revista Econômica do Nordeste. Fortaleza, 41(4), 731-740.

Portaria $n^{\circ}$ 4, de 5 de janeiro de 2016. Retifica a Portaria $n^{\circ} 337$ de 18 de setembro de 2015 que Dispõe sobre a alteração daaquisições de matérias-primas oriundas das cooperativas agropecuárias do agricultor familiar. MDA - Ministério do Desenvolvimento Agrário. Disponível em http:/ / www.mda.gov.br/sitemda/sites/sitemda/files/ user_img_873/Portaria\%20MDA\%20n\%C2\%BA\%204_2016\%20Retifica \%20a\%20Po rtaria\%20MDA\%20337.pdf

Scott, J. (2002). Los dominados y el arte de la resistência. México: Ediciones Era.

Silva, M. E. S. (2019). A política pública do biodiesel e os desafios para a inclusão dos diferentes estilos de agricultura familiar no mercado dos biocombustíveis no Brasil (tese de doutoramento). Instituto de Filosofia e Ciências Humanas Faculdade de Arquitetura da Universidade Federal Rio Grande do Sul, Porto Alegre. Disponível em https://lume.ufrgs.br/handle/10183/201530

Spink, M. J., \& Lima, H. (2000). Rigor e visibilidade: A explicitação dos passos da interpretação. Em M. J. Spink (Org.), Práticas discursivas e produção de sentidos no cotidiano: Aproximações teóricas e metodológicas (pp. 71-99). São Paulo: Cortez.

Wanderley, M. N. B. (1998). Raízes históricas do campesinato brasileiro. Em J. C. Tedesco (Org.), Agricultura familiar: Realidade e perspectivas. Passo Fundo: UPF.

Woortmann, K.,Suarez, M., \&Veloso, M. (1983). Introdução ao Seminário “Saber e Reprodução Camponesa". Anuário Antropológico, 81, 149-156.

Data de submissão: 31/01/2020 | Data de aceitação: 15/05/2020 